\title{
Effect of Nursing Intervention Program related to Nursing Iatrogenic Events on Nurses Performance and Clinical Outcomes of Neonates at Neonatal Intensive Care Unit
}

\section{Fatma Al Zahra Shebl Salah ${ }^{1}$, Ebtisam Mohamed Elsayed ${ }^{2}$, Hamed Mohamed Elsharkawy ${ }^{3}$, Sabah Mohamed sharshor ${ }^{4}$}

${ }^{1}$ Master of pediatric nursing, Faculty of Nursing/Ain Shams University, Egypt

${ }^{2}$ Professor of Pediatric Nursing, Faculty of Nursing/ Tanta University, Egypt

${ }^{3}$ Professor of Pediatric, Faculty of Medicine/ Tanta University, Egypt

${ }^{4}$ Assistant Pro. of pediatric Nursing, Faculty of Nursing/ Tanta University, Egypt

\begin{abstract}
Background: Iatrogenic events that cause harm to neonates in NICU is characterized as adverse events. Neonates are a particularly vulnerable population and may be at further risk of harm from medical errors because of their low birth weight, physiological immature, limited compensatory abilities and extensive exposure to medication in NICU. Nurses are the first line of defense to safeguard against iatrogenic errors. Aim of this study was to evaluated the effect of educational intervention program on nurses' performance and clinical outcomes of neonates related to nurses' iatrogenic at neonatal intensive care unit. Subjects and method The study was conducted at Neonatal Intensive Care Unit of Tanta University hospital. A quasi-experimental design was used. Sample All nurses (57) working in the previously mentioned setting were included the study and all neonates admitted within six months. Tools: Three tools were used to collect the required data; Structured Interview schedule, It was consisted of two parts, part one was biosocial data of nurses, neonate and part two was nurses' knowledge (tool I). Observation checklist to assess nurse's practice regarding iatrogenic errors at NICU (tool II). Neonate's clinical outcomes schedule to assess outcomes of neonate post program (tool III). Results of the study revealed that, before program the total knowledge scores of all nurses were poor while majority of them had good scores after implementing program. Total practice scores of all nurses were good also immediately and after one month. There were statistical significant difference between nursing knowledge, practice and biosocial data. The outcome of neonates showed an improvement in neonatal condition of discharge. Conclusion Intervention program was effective and improving nurses' knowledge and practice as well as reducing iatrogenic errors at NICU. Recommendations were suggested that establish continuous monitoring system to assess nurses practice in NICU settings especially for iatrogenic errors.
\end{abstract}

Key wards: Iatrogenic Events, Nurses' Performance, Clinical Outcomes, Neonatal Intensive Care Unit, Intervention Program. 


\section{Introduction}

Iatrogenic errors is defined as adverse condition occurring as a result of a diagnostic procedure or treatment by a medical team including physicians, nurses, technicians, laboratories, and anyone involved in neonatal care. Iatrogenic that cause harm to neonates in neonatal intensive care unit are characterized as adverse events and it can lead to morbidity and mortality that could be prevented. ${ }^{(1,2)}$ Iatrogenic events can be cause harmful effect to neonates at NICU. Neonates are a particularly vulnerable population and high risk of harm from medical errors because of small body size, weight-based dosages, off-label drug usage, availability of stock solutions in a variety of concentrations, inability to communicate with providers, and immature body organs affecting drug absorption, distribution, metabolism, and excretion. $^{(3)}$

Iatrogenic effect has been increasingly seen in the neonatal intensive care unit. In addition, increased awareness and the introduction of more appropriate quality control measures have resulted in higher levels of suspicion about and increased recognition of complications associated with delivery of care. The incidence of iatrogenic effect also rises with the increased length of hospital stay and level of immaturity. Approximately half of the iatrogenic effect is related to medication error. The other iatrogenic effects are due to nosocomial infections, insertion of invasive procedure, prolonged mechanical ventilation, administration of parenteral nutrition, skin damage and environmental hazards. ${ }^{(4)}$

The incidence of iatrogenic event estimated to be 20 to 26 per 1000 neonate, and many of these events were described as preventable, because $30 \%$ to $50 \%$ of such events are harmful, iatrogenic events may have a considerable impact on neonates morbidity. Among the iatrogenic reported in the various studies reviewed, medication errors were the most frequent error type. World health organization, 2015 was estimated that 1 in 10 patients worldwide are affected by medical errors. $^{(5)}$

Neonatal nursing is considered a specialty area, requiring specialized knowledge and training. By adhering to recognized and accepted internal and external policies, neonatal nurses will uphold the standard of care set for their area of practice and avoid legal liability. ${ }^{(6)}$

\section{Aim of the Study}

This study aimed to evaluate the effect of educational intervention Program about iatrogenic errors on nurses' performance and clinical outcomes of neonates at NICU. 


\section{Subjects and Method}

This is a quasi experimental research design. The study was conducted at; Neonatal Intensive Care Unit of Tanta University hospital which contain 30 incubators. All nurses (57) working in the previously mentioned setting were included in this study and all neonates admitted within six months.

\section{Three tools were used to collect data:}

Tool I: Structured Interview schedule.

It was consisted of two parts:

\section{Part one: - Biosocial data of Nurses such}

as: age, educational level, years of experience and any training program about neonatal care.

- Biosocial data of Neonate such as: age, sex, date of admission and diagnosis

Part two: - Nurses' Knowledge about iatrogenic errors at neonatal intensive care unit such as: (Definition, Type, Causes of iatrogenesis, How to improve neonatal safety in the NICU and prevent common adverse events).

\section{Scoring system for nurses' knowledge:}

Aquestionnaire including 4 sections with the total items 21each item was as follow: the definition of iatrogenesis (1 item), type of iatrogenesis in NICU (18item), causes of iatrogenesis (1 item), How to improve neonatal safety in the NICU and prevent common adverse events (1 item).

Three level of scoring for question were used: Correct and complete answer was scored (2), Correct and incomplete answer was scored (1) and Don't know or incorrect answer was scored (0)

\section{The total scores of nurses' knowledge} were classified as follows: Poor level scored $<65 \%$, Fair level scored $>65 \%$ to $<75 \%$ and Good level scored $>75 \%$.

\section{Tool II: Observation Checklist}

This tool was developed by (Wong's $2003)^{(7)}$ and adapted and modified by researcher after reviewing the relevant literature to assess nurse's practice about iatrogenic errors at NICU includes:

1- infection control which contain hand washing before and after contact with neonate, handling contaminated item and collecting a specimen. Personal protective equipment. Safe handling and disposal of sharps. Environmental clean or disinfect or sterile. Use aseptic technique. Isolate infected neonate.

2- Medication administration including the 5 rights (neonate name, medication, dose, route of administration, time and frequency)

3- Mechanical ventilation includes check parameter of ventilator, suitable position of endotrachial tube, device connections are well connected with each other and Dispose of condensate water vapor on the inner walls of device connection and Note the presence of skin lesions around the nasal or lips location of the fixation 
and Change the location of the installation from right to left and vice versa daily and Make physical therapy of the chest and Suction by using the largest catheter is possible to enter the laryngeal tube.

4- Phototherapy errors include Cover eye and genital organ, Monitor neonate's body temperature, Change his position every 2 hours.

5-Record and report errors :Record nursing notes every shift and explain by details all about neonate to follow their progress, Nursing care plan should be record suction, physiotherapy, and check feeding intolerance signs, intake and output and incubator temperature.-Initial assessment on admission as (anthromeasurement, vital signs and physical examination) should be recorded.

6-Invasive procedure errors include Peripheral IV line placement, Heel prick and capillary blood sampling and Arterial blood sampling.

\section{Scoring system for nurses' practice:}

Each item in the check list was scored as following Complete done was scored (2), Incomplete done was scored (1) and Not done was scored $(0)$.

The total scores of nurses' practice were classified as follows More than $75 \%$ was considered satisfactory and Less than $75 \%$ was considered unsatisfactory.
Tool I, II were used three time before, immediate and after one month of conducting the educational program.

\section{Tool III: Neonate's clinical outcomes}

schedule: It was developed by (Wong's 2003) (7) and modified by the researcher after reviewing the relevant literature and used to assess neonate's condition post intervention program. It was included hospital stay at NICU and Condition at discharge (Improved or Died).

\section{Method}

The study was accomplished through the following steps:

1- Administrative process: Official approval was obtained from the hospital administrative authorities of the previously mentioned setting after explanation the aim of the study to get their cooperation and acceptance.

\section{2- Ethical considerations:}

Approval from ethical commity to conduct this study are obtained. Confidentiality and privacy regarding data collection were taken into consideration. The researcher emphasized that participation in the study is voluntary and anonymous and nurses have the right to withdraw at any time. Informed consent was taken from all nurses working in the previously setting. Nature of the study was not causing any harm or pain to entire sample. 
3-A pilot study was carried out before starting the data collection. It was done on a sample of $10 \%$ to evaluate the clarity and applicability of the research tools and the necessary modifications was done. Pilot study was excluded from the study sample.

4- Content validity was done by five experts in the field of the study.

5-Reliability of the tools was done using appropriate test.

\section{6-Tools development: structured} questionnaire sheet consisted of three tools collection; Tool (I) was developed by the researcher after reviewing relevant literatures and used to collect biosocial data of nurses and neonates as well as to assess nurses' knowledge about iatrogenic errors at neonatal intensive care unit. Tool (II) was adapted and modified by the researcher to assess nurse's practice regarding iatrogenic errors at NICU, It was used three times before, immediately and after one month of data collection. Tool (III) was adapted and used to assess clinical outcomes of neonate after applications of the intervention program.

7-Data collection was conducted in three phases as follows:

1. Assessment phase: To assess nurses' knowledge about nurses' iatrogenic at NICU using Tool (I) part 2 before apply the educational program.
2. Planning phase: Each nurse was observed by the researcher at different shift to evaluate their practices regarding to iatrogenic errors at NICU using Tool II. Teaching program was applied to all nurses through five sessions, Nurses were divided into six groups (each group consisted of ten nurses). The time for each session was ranged from 30- 45 minutes. Teaching methods were used when conducting session educational Group discussions, demonstration and re demonstration, power point presentation and audiovisual material were used to facilitate their learning.

\section{Implementation phase: First session:} covered the following topics: Definition, Type and Causes of iatrogenic errors at NICU. Second session: focused on How to improve neonatal safety in the NICU and prevent common adverse events. Third session: concentrated on as nurse's practice regarding to infection control and medication administration at NICU.

Fourth session: demonstrating mechanical ventilation and phototherapy. Five sessions: it was concentrated on invasive procedure and demonstrating record and report at NICU.

4. Evaluation phase: Each nurse was evaluated by the researcher post tested on an individual basis to assess their knowledge and practice about iatrogenic 
errors at NICU using Tool I part 2 and

Tool II. Each neonate in NICU was evaluated using Tool III. The data were collected within 6 month from the beginning of february2020 to july2020.

\section{Results}

Table (1): demonstrates the percentage distribution of biosocial data of the studied nurses. It was found that, the mean age of the participant nurses was $31.017 \pm 6.629$. Regarding educational level, it was found that, less than half of nurses $(43.9 \%)$ had Bachelor degree of nursing science, while about (22.8\%) had Technical Nursing Institute and (33.3\%) had Nursing school. Concerning their years of experience, it was observed that, the mean years of experience were $7.333 \pm 6.985$. Regarding to Previous training program, it was found that two third of nurses $(64.9 \%)$ had training about neonatal care.

Table (2): demonstrates the percentage distribution of biosocial data of the studied neonates. It was found that, the mean age was12.430 \pm 8.757 days. Regarding their gender, it was found that, $48.0 \%$ of neonates were male, while $52.0 \%$ were female. Concerning Diagnosis, it was observed that, less than one third $30.0 \%$ of neonates had Low birth weight followed by jaundice $29.0 \%$, Infant of diabetic mother $10.0 \%$, Respiratory distress syndrome $18 \%$, Pneumonia $9 \%$ and only $4 \%$ had Transnet tachypnea of neonates.

Figure (1) illustrates total nurses' knowledge about iatrogenic errors at neonatal intensive care unit, it was found that, before program slightly more than three quarters of nurses (77.2\%) were poor while after one month of the program implementation, the answer of majority nurses $(98.3 \%)$ were good, There were a statistical significant difference between nurses knowledge about iatrogenic at neonatal intensive care unit $(\mathrm{P}<0.05)$.

Figure (2) illustrated scores of total nurses' practice about iatrogenic errors at neonatal intensive care unit. It was noticed that, the mean score of nurses' practice were $64.35 \pm 5.05$ before the program implementation, compared by $84.97 \pm 2.46$, and 78.84 \pm 4.39 immediate and after one month of the program implementation respectively. There were improvement in total nurses' practice scores immediately and one month compared by before the program. With a statistical significant difference $(\mathrm{P}=0.0001)$.

Table (3) illustrates that percent distribution of neonate's clinical outcomes post intervention program regarding length of hospital stay at NICU and condition at discharge, it was detected that, the mean score to length of hospital stay at NICU 
were $16.690 \pm 8.66$, and $94 \%$ of neonates

at discharge were improved.

Table (4): clarifies the correlation between total nurses' knowledge score and practice before, immediate, and after one month of the program implementation. It was found that, before the program implementation $57.8 \%$ of nurses had poor knowledge and unsatisfactory practice scores while as all of them $(100.0 \%)$ and the majority of them (98.3\%) had good knowledge and satisfactory practice scores immediately and one month after the program implementation respectively. There were a statistical significant difference between immediate, and after one month of the program implementation $(\mathrm{P}$ value $>0.05)$.

Table (5): Show relation between mean of total nurses' knowledge and practice scores and their biosocial data. It was found that Mean \pm SD were 15.296 \pm 4.36 and 12.148 \pm 5.76 immediate than before and after one month than before program for total knowledge score of the age between $25-<35$ years of the studied nurses while Mean \pm SD were 21.148 \pm 4.85 and 19.000 \pm 6.12 immediate than before and after one month than before program for total practice score. There were a statistical significant difference between mean of total nurses' knowledge and practice scores and their biosocial data $(\mathrm{P}$ value $>0.05$ ). 
Table (1): Percent distribution of studied nurses regarding biosocial data

\begin{tabular}{|c|c|c|}
\hline \multirow{2}{*}{ Biosocial data of studied nurses } & \multicolumn{2}{|c|}{$(\mathbf{n}=57)$} \\
\hline & No & $\%$ \\
\hline \multicolumn{3}{|l|}{ Age (years): } \\
\hline$<25$ & 12 & 21.0 \\
\hline $25-<3535-45$ Range & 27 & 47.4 \\
\hline \multirow[t]{3}{*}{ Mean \pm SD } & 18 & 31.6 \\
\hline & \multicolumn{2}{|c|}{$20-45$} \\
\hline & \multicolumn{2}{|c|}{$31.017 \pm 6.629$} \\
\hline \multicolumn{3}{|l|}{ Educational level } \\
\hline Nursing school (3 years) & 19 & 33.3 \\
\hline Health Technical Institute & 13 & 22.8 \\
\hline Bachelor of nursing & 25 & 43.9 \\
\hline \multicolumn{3}{|l|}{ Years of experience } \\
\hline$<10$ & 40 & 70.2 \\
\hline $10-<20$ & 10 & 17.6 \\
\hline $20-<30$ & 7 & 12.2 \\
\hline Range & \multicolumn{2}{|c|}{$1-23$} \\
\hline Mean \pm SD & \multicolumn{2}{|c|}{$7.333 \pm 6.985$} \\
\hline \multicolumn{3}{|l|}{ Previous training program } \\
\hline No & 8 & 14.0 \\
\hline Basic life support & 9 & 15.7 \\
\hline Infection control & 10 & 17.6 \\
\hline Neonatal care & 37 & 64.9 \\
\hline Ventilator care & 4 & 7.0 \\
\hline
\end{tabular}


Table (2): Percent distribution of studied neonates regarding biosocial data

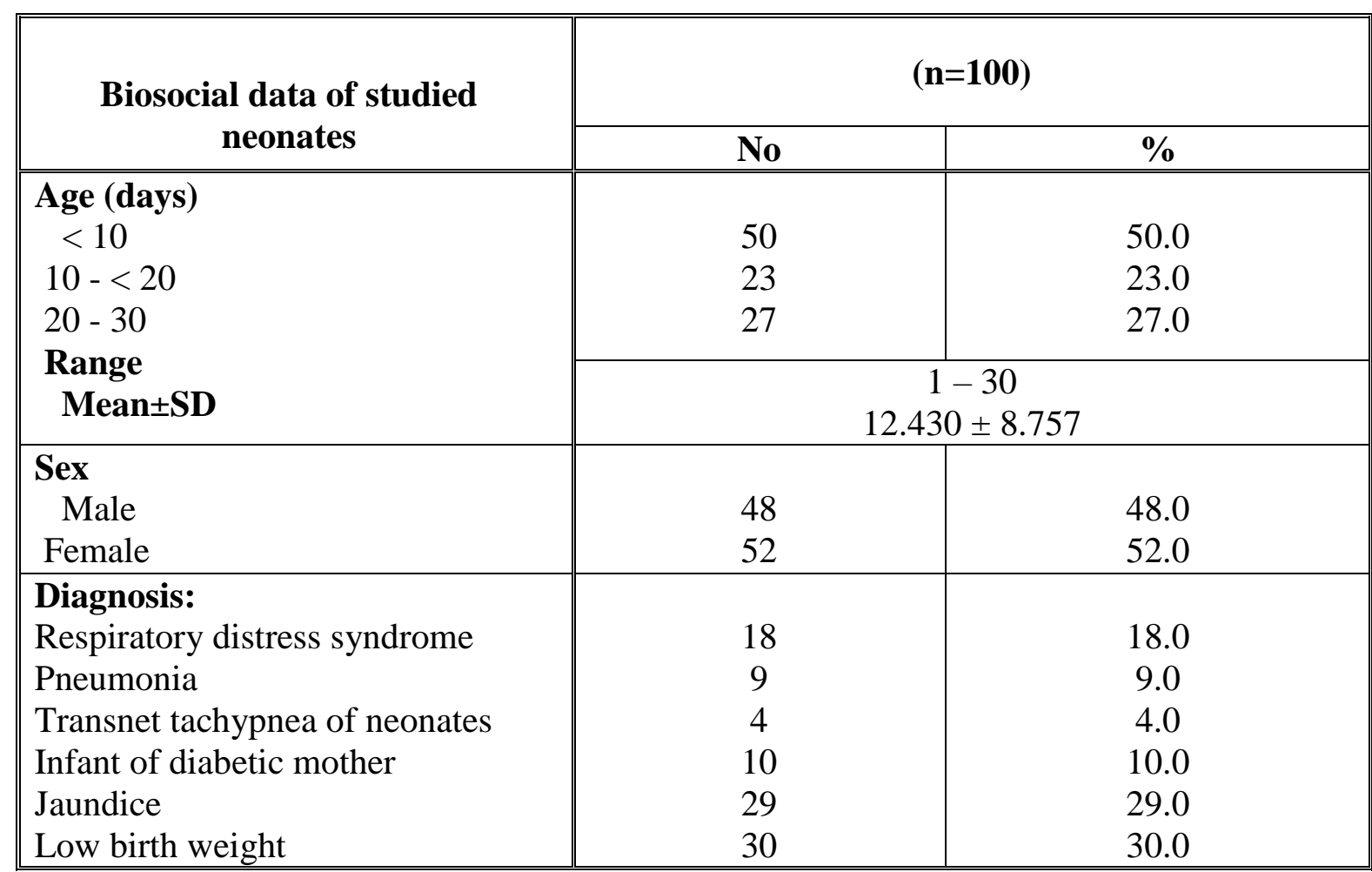

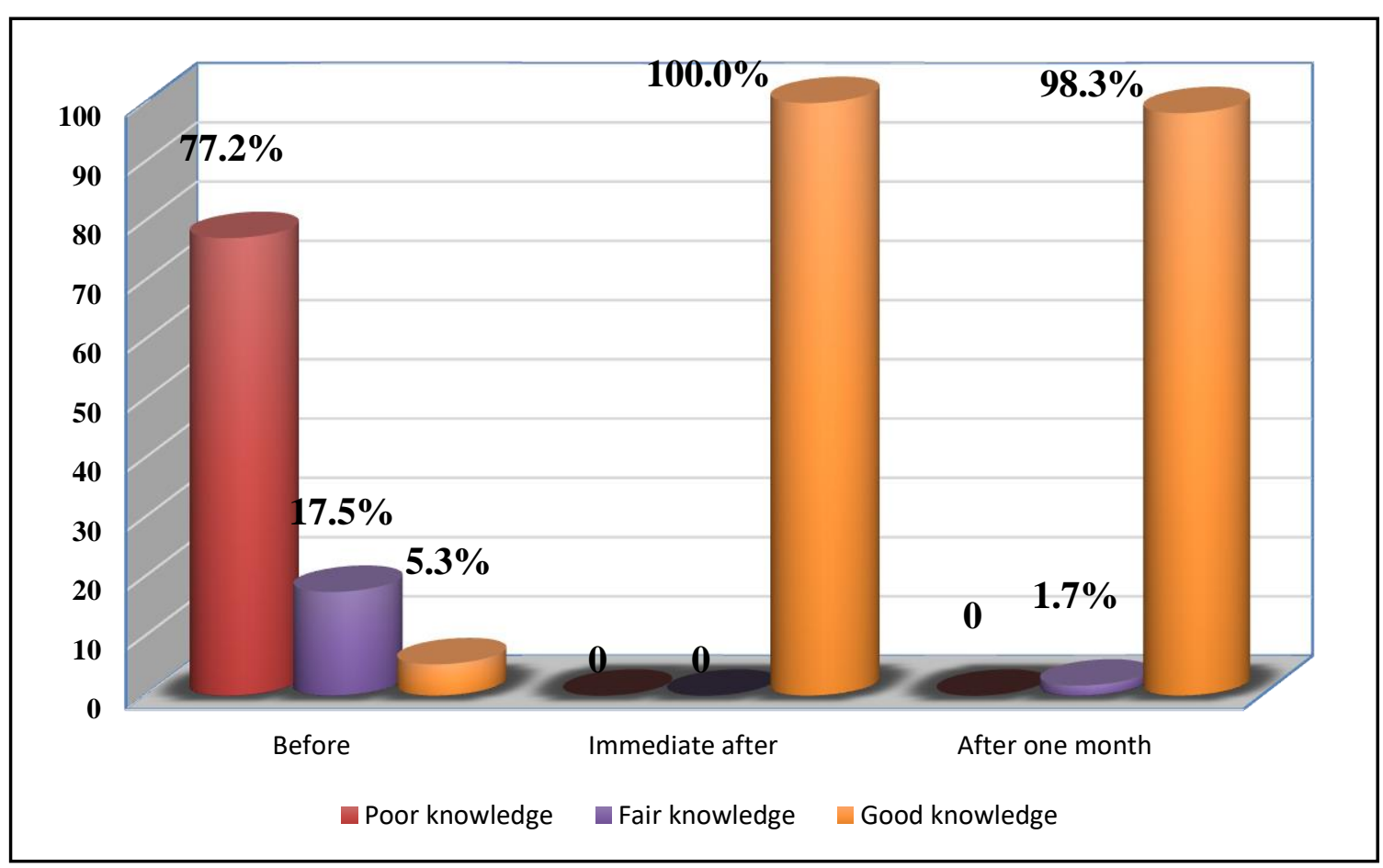

- Some neonates had more than one problem.

Figure (1): Total scores of nurses' knowledge about iatrogenic errors at neonatal intensive care unit 


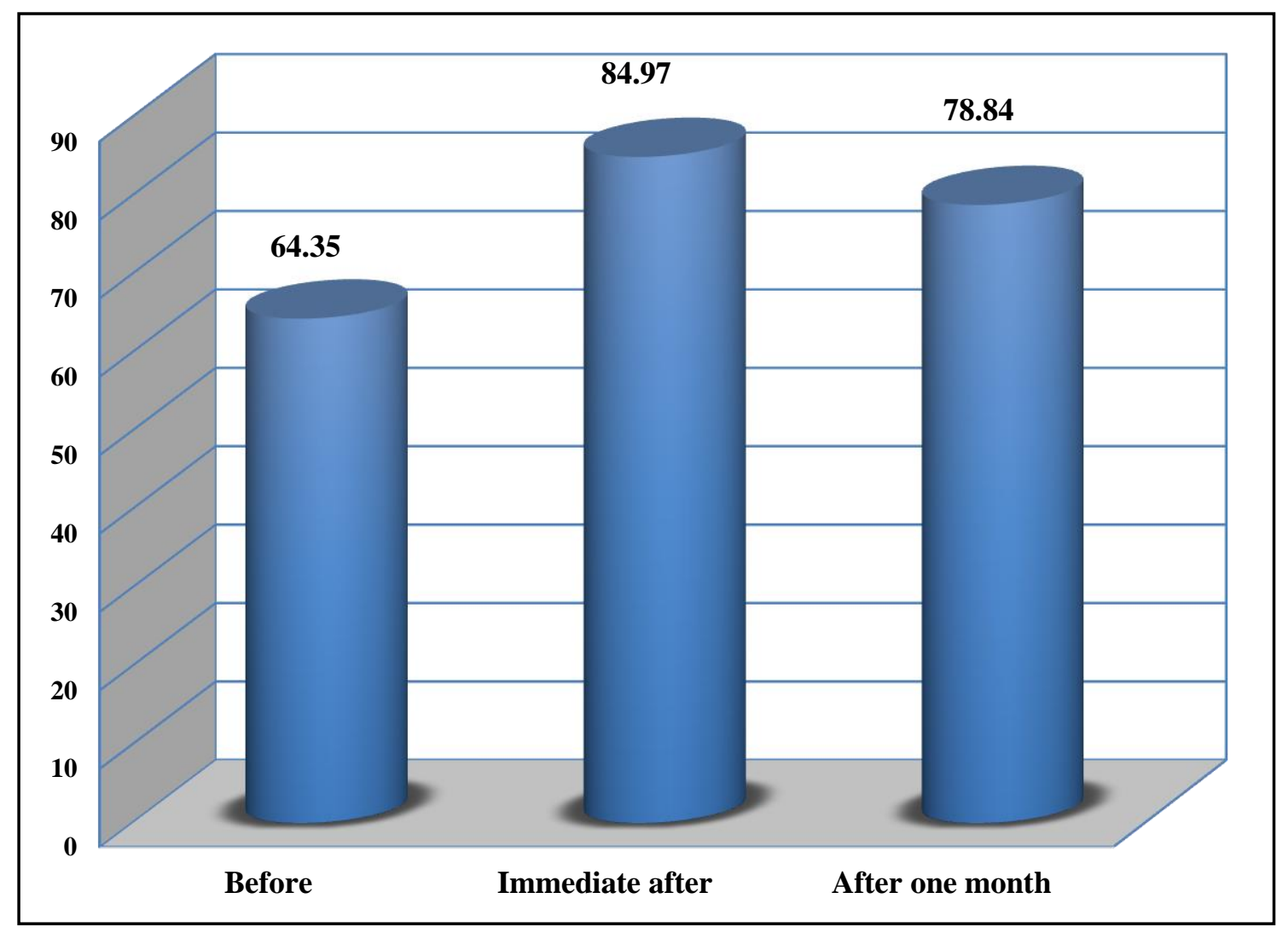

Figure (2): Scores of total nurses' practice about iatrogenic errors at NICU.

Table (3): Percent distribution of neonate's clinical outcomes related to length of hospital stay at NICU and condition at discharge post educational program.

\begin{tabular}{|c|c|c|}
\hline \multirow[t]{2}{*}{ Nursing assessment } & \multicolumn{2}{|c|}{$\begin{array}{c}\text { Neonate's clinical outcomes post educational } \\
\text { program }(n=100)\end{array}$} \\
\hline & $\mathbf{N}$ & $\%$ \\
\hline \multicolumn{3}{|l|}{$\begin{array}{l}\text { Length of hospital stay at NICU } \\
\text { (days) }\end{array}$} \\
\hline$<10$ & 27 & 27.0 \\
\hline$<20$ & 40 & 40.0 \\
\hline$<30$ & 20 & 20.0 \\
\hline$<40$ & 13 & 13.0 \\
\hline $\begin{array}{l}\text { Range } \\
\text { Mean } \pm \text { SD }\end{array}$ & \multicolumn{2}{|c|}{$\begin{array}{c}3-34 \\
16.690 \pm 8.66\end{array}$} \\
\hline $\begin{array}{l}\text { Condition at discharge } \\
\text { Improved } \\
\text { Died }\end{array}$ & $\begin{array}{c}94 \\
6\end{array}$ & $\begin{array}{c}94.0 \\
6.0\end{array}$ \\
\hline
\end{tabular}


Table (4): Correlation between nurses' knowledge scores and practice about iatrogenic errors at NICU.

\begin{tabular}{|c|c|c|c|c|c|c|c|c|}
\hline \multirow{3}{*}{ Total practice level } & \multicolumn{6}{|c|}{ Total knowledge level } & \multirow{3}{*}{$\mathbf{R}$} & \multirow{3}{*}{$\mathbf{P}$} \\
\hline & \multicolumn{2}{|c|}{ Poor Knowledge } & \multicolumn{2}{|c|}{ Fair Knowledge } & \multicolumn{2}{|c|}{ Good knowledge } & & \\
\hline & No & $\%$ & No & $\%$ & No & $\%$ & & \\
\hline $\begin{array}{l}\text { Levels of total practice } \\
\text { before program. }\end{array}$ & & & \multirow{3}{*}{$\begin{array}{c}0 \\
10\end{array}$} & \multirow{3}{*}{$\begin{array}{c}0.0 \\
17.6\end{array}$} & & & \multirow{4}{*}{0.403} & \multirow{4}{*}{$0.002 *$} \\
\hline Unsatisfactory practice & 33 & 57.8 & & & 0 & 0.0 & & \\
\hline Satisfactory practice & 11 & 19.3 & & & 3 & 5.3 & & \\
\hline $\begin{array}{l}\chi^{2} \\
P\end{array}$ & \multicolumn{6}{|c|}{$\begin{array}{l}23.156 \\
0.000 *\end{array}$} & & \\
\hline $\begin{array}{l}\text { Levels of total practice } \\
\text { immediate after } \\
\text { program. }\end{array}$ & & & & & & & \multirow{4}{*}{0.465} & \multirow{4}{*}{$0.0001 *$} \\
\hline Unsatisfactory practice & 0 & 0.0 & 0 & 0.0 & 0 & & & \\
\hline Satisfactory practice & 0 & 0.0 & 0 & 0.0 & 57 & 0.0100 .0 & & \\
\hline $\begin{array}{c}\chi^{2} \\
\mathbf{P}\end{array}$ & \multicolumn{6}{|c|}{$\begin{array}{l}-- \\
--\end{array}$} & & \\
\hline $\begin{array}{l}\text { Levels of total practice } \\
\text { one month after } \\
\text { program. }\end{array}$ & & & & & & & \multirow{4}{*}{0.382} & \multirow{4}{*}{$0.006^{*}$} \\
\hline Unsatisfactory practice & 0 & 0.0 & 0 & 0.0 & 0 & 0.0 & & \\
\hline Satisfactory practice & 0 & 0.0 & 1 & 1.7 & 56 & 98.3 & & \\
\hline$\underset{\mathbf{P}}{\chi^{2}}$ & \multicolumn{6}{|c|}{--} & & \\
\hline
\end{tabular}

* Statistically Significant difference at $(\mathbf{P}<0.05)$ 
Table (5): Relation between changes in mean of total nurses' knowledge and practice scores and their biosocial data immediate and one month after than before the program intervention.

\begin{tabular}{|c|c|c|c|c|c|c|c|c|}
\hline \multirow{3}{*}{ Biosocial data } & \multicolumn{4}{|c|}{ Total knowledge score $(\mathbf{n}=57)$} & \multicolumn{4}{|c|}{ Total practice score $(n=57)$} \\
\hline & \multicolumn{2}{|c|}{$\begin{array}{l}\text { Changes immediate } \\
\text { after than before }\end{array}$} & \multicolumn{2}{|c|}{$\begin{array}{c}\text { Changes after one month } \\
\text { than before }\end{array}$} & \multicolumn{2}{|c|}{$\begin{array}{l}\text { Changes immediate } \\
\text { after than before }\end{array}$} & \multicolumn{2}{|c|}{$\begin{array}{c}\text { Changes after one month } \\
\text { than before }\end{array}$} \\
\hline & Mean \pm SD & $\begin{array}{c}\mathbf{F} \text { value } \\
\mathbf{P}\end{array}$ & Mean \pm SD & $\begin{array}{c}\text { F value } \\
\mathbf{P}\end{array}$ & Mean \pm SD & $\begin{array}{c}\text { F value } \\
\mathbf{P}\end{array}$ & Mean \pm SD & $\begin{array}{c}\text { F value } \\
\mathbf{P}\end{array}$ \\
\hline $\begin{array}{l}\text { Age in years: } \\
<25 \\
25-<35 \\
35-45 \\
\end{array}$ & $\begin{array}{l}13.666 \pm 4.20 \\
15.296 \pm 4.36 \\
15.888 \pm 4.45 \\
\end{array}$ & $\begin{array}{l}0.967 \\
0.387\end{array}$ & $\begin{array}{l}11.250 \pm 4.57 \\
12.148 \pm 5.76 \\
13.333 \pm 4.72 \\
\end{array}$ & $\begin{array}{l}0.604 \\
0.550\end{array}$ & $\begin{array}{l}22.833 \pm 5.18 \\
21.148 \pm 4.85 \\
18.277 \pm 6.05 \\
\end{array}$ & $\begin{array}{c}2.907 \\
0.063 *\end{array}$ & $\begin{array}{l}14.629 \pm 5.81 \\
19.000 \pm 6.12 \\
11.333 \pm 6.09 \\
\end{array}$ & $\begin{array}{c}5.955 \\
0.005 *\end{array}$ \\
\hline $\begin{array}{l}\text {-Education level: } \\
\text { Nursing School (3years) } \\
\text { Health Technical Institute } \\
\text { Bachelor of Nursing Science }\end{array}$ & $\begin{array}{l}13.631 \pm 4.57 \\
15.153 \pm 4.05 \\
16.280 \pm 4.15\end{array}$ & $\begin{array}{l}2.067 \\
0.136\end{array}$ & $\begin{array}{l}11.000 \pm 5.72 \\
11.769 \pm 5.57 \\
13.640 \pm 4.40\end{array}$ & $\begin{array}{l}1.524 \\
0.227\end{array}$ & $\begin{array}{l}19.400 \pm 5.86 \\
21.384 \pm 4.80 \\
21.631 \pm 5.42\end{array}$ & $\begin{array}{l}1.062 \\
0.353\end{array}$ & $\begin{array}{l}12.640 \pm 6.09 \\
13.615 \pm 6.83 \\
17.578 \pm 5.85\end{array}$ & $\begin{array}{c}3.611 \\
0.034^{*}\end{array}$ \\
\hline $\begin{array}{l}\text { - Years of experience: } \\
<10 \\
10-<20 \\
20-<30\end{array}$ & $\begin{array}{l}14.675 \pm 4.34 \\
15.600 \pm 5.05 \\
17.142 \pm 3.18\end{array}$ & $\begin{array}{l}1.022 \\
0.367\end{array}$ & $\begin{array}{l}11.825 \pm 5.32 \\
13.100 \pm 4.67 \\
14.142 \pm 5.27\end{array}$ & $\begin{array}{l}0.719 \\
0.492\end{array}$ & $\begin{array}{l}21.500 \pm 5.00 \\
18.800 \pm 7.40 \\
18.000 \pm 4.39\end{array}$ & $\begin{array}{l}1.909 \\
0.158\end{array}$ & $\begin{array}{c}15.775 \pm 6.22 \\
11.500 \pm 6.51 \\
11.57 \pm 6.29\end{array}$ & $\begin{array}{l}2.725 \\
0.075\end{array}$ \\
\hline
\end{tabular}

*Statistically Significant difference at $(\mathbf{P}<0.05)$ 


\section{Discussion}

Iatrogenic error that cause harm to neonates in neonatal intensive care unit are characterized as adverse events and it can lead to morbidity and mortality that could be prevented. ${ }^{(4)}$ Iatrogenic errors affect one in ten newborn worldwide, and their implications may include death, permanent or temporary harm and financial loss. ${ }^{(8)}$

Neonate safety is a worldwide priority aimed at preventing medical errors before they cause death, harm, or injury.

Nursing education focus on prepare nurses for the future, as health care is dynamic. Nurses need for both strong theoretical background and an equal amount of handson clinical experience. ${ }^{(9)}$

The present study revealed that, one third of studied neonates were low birth weight infants. This may be due to that low birth weight infants need complex care, often critically ill, requiring intensive treatments, assisted ventilation, and prolonged length of stays, factors that independently increase their risk of adverse events including iatrogenic errors. ${ }^{(10)}$ The current findings are go in the same line with Kugelman (2018), EL Meneza (2018), Kanter(2014) who reported that higher incidence of iatrogenic errors occurring during the care of preterm infants and low birth weight infants. There were a significant inverse correlation between, birth weight and iatrogenic errors. $(11,12,13)$
In the current study, It was observed that, most of nurses' answer about iatrogenic errors were incorrect before implementing the intervention program while their knowledge improved after implementing of intervention program, it can be explained that, this improvement occurs because nurses need continuous instruction and resource to be educated and updated their knowledge.

The results of present study revealed that total nurses' practice scores were satisfactory practice immediately and one month compared by before the program nearly half of nurses' practice were satisfactory practice with a statistical significant difference.

This result was in an agreement with Aboalyzeed (2019) who found that, the total practice scores of all nurses' were poor before implementing practice guidelines. While all nurses' practice were good immediately after application of the practice guidelines and half of nurses' practice were good one month later with statistical significant difference. ${ }^{(14)}$ The results of the present study revealed that, there was statistically significance correlation between nurses' practice and their knowledge after implementing program. Knowledge and practice were improved parallel; this reflects the importance of integration between theory and practice providing an optimum 
learning and facilitates the acquisition of the clinical skills of nursing. Also this may be related to the highly expressed need of this group of nurses to learn more about iatrogenic errors.

This finding was in agreement with Gijare (2012), and Hamid et al., (2015), who found that statistically significant positive correlation between nurses' knowledge and practice about iatrogenic errors. $(15,16)$ While Askarian et al., (2017), and Najeeb \& Taneepanichsakul (2016) contradicted with the current finding and they mentioned that no correlation between knowledge and practice (17, 18) $^{(10}$

Regarding the relation between biosocial data of nurses and their knowledge and practice about iatrogenic errors before, immediate and one month after implementing program guidelines the study revealed that, a statistically significance relation between nurses' knowledge and practice and their biosocial data. This may be related to that total number of bachelor degree of nursing was nearly half of them and, nearly half of them was aged between $25-<35$ years.

From my point of view the good instruction availability of resource audiovisual are very important to facilitate their understanding and reflect on good practice. it may be because their age were between 25 - < 35years or their educational level were bachelor of nursing science or their experience were less than 10 years, all together helping to understand the instruction and improve their practice. This finding was disagree with by Abdel Aziz (2014) who mentioned that no significance relation between nurses' knowledge and their biosocial data. As well Gijare (2012) reported no significant statistical difference in pre and post test knowledge \& practice scores of various age groups and different years of experience. ${ }^{(19,14)}$

\section{Najeeb \& Taneepanichsakul (2016)} reported a negative relationship between knowledge and practice regarding infection control among nurses and doctors. Moreover, age and years of experience of the studied group, were negatively correlated with their knowledge and practice of infection control. In this regards Alwutaib et al., (2012) revealed that, older age is an important determinant of lower level of knowledge score. ${ }^{(20,17,18)}$ As well Gijare (2012) reported no significant statistical difference in pre and post test knowledge \& practice scores of various age groups and different years of experience. ${ }^{(15)}$

Finally the outcome of neonate improved after program compared with pre program. The hospital stay became short period after program was given, this indicated also the good instruction was benefit to the neonate 
and reflect the nurses' knowledge and practice.

\section{Conclusion}

Based on the findings of the present study, it can be concluded that nurses' knowledge and practices about iatrogenic errors were improved after program implementation.

There were a statistical significant difference between nurses' knowledge, practice and their biosocial data before, immediate and after one month of the educational program.

\section{Recommendations}

Based upon the findings of the current study the following recommendations were suggested:

-Establish continuous evaluation system to evaluate nurses' knowledge and practice about iatrogenic errors at NICU.

- Conducting continuous in service training program to nurses for update their knowledge and practice about iatrogenic errors at NICU.

-Further researches should be conducted about iatrogenic errors to find out the most errors in different pediatric care setting.

\section{References}

1. Amir K, Esther I, Eric S, Imad R, Meiron L. Neonatal Nurse Official journal of the American Academy of Pediatrics . 2013; 122(3): 550- 555.
2. Safaa E. Iatrogenic Hazards in Neonatal Intensive Care Unit. February 2013

3. Gray JE and Ringer SA. Common neonatal procedures. Manual of NeonatalCare. 6th ed. Baltimore, MD: Lippincott Williams \& Wilkins: 2014; Page: 687-702.

4. Luciana D, Marismary H ,Carla L, Walter V. Adverse events and incidents in neonatal intensive care units. $\mathbf{J}$ neonates 2013; 94(3): 937- 945.

5. World Health Organization. WHO launches -Nine patient safety solutions.2010.

6. Palmero D, Di Paolo ER, Beauport L, Pannatier A, Tolsa JF. A bundle with a preformatted medical order sheet and an introductory course to reduce prescription errors in neonates. Eur $\mathbf{J}$ Pediatr. 2016; 175:113-119. doi: 10.1007/s00431-015-2607-4.

7. Wong's. Nursing care of infant and children, 8th ed Hockenberry, Wilson, Canada 2003 PP 393-396, 327-332.

8. Samra HA, McGrath JM and Rollins W . Patient Safety in the NICU. J Perinat Neonat Nurs. 2015;25(3):123-32.

9. Cheek J, Jones D. What nurses say they do and need: Implications for the educational preparation of nurses, Journal of Nurse Education, 2013; 23(3): 40-50. 
10. Ligi I.,. "Iatrogenic events in admitted neonates: a prospective cohort study". Lancet journal of Paediatric.2018;37 (371): 404-410.

11. Kugelman A., "Iatrogenesis in neonatal intensive care units: observational and interventional, prospective, multicenter study". Journal of Paediatric.2018; 122(3) : $550-555$.

12. EL Meneza s Analysis and Identifying Risk Profile for Medication Errors in the Neonatal Intensive Care Units journal of Paediatric . $2018 ; 7$ (7): 669-84

13. Kanter DE, Turenne W, Slonim AD. Hospital-reported medical errors in premature neonates. Pediatr Crit Care Med. 2014;5(10):119-23

14. Aboalyzeed s Elsayed e, Elsharkawy h. Effect of Implementing Practice Guidelines Regarding Medication Administration Iatrogenic Events on Nurses' Performance at Neonatal Intensive Care Unit Tanta Scientific Nursing Journal. 2017;13(2):47-59.

15. Gijare M, (2012). Effectiveness of teaching on infection control practices among health care professionals. Sinhgad e Journal of Nursing,2012; 2(2): 5-9.

16. Hamid M.Z.A., Aziz N.A., Anita A.R., Norlijah O., (2015). Knowledge of blood-borne infectious diseases and the practice of universal precautions amongst health-care workers in a tertiary hospital in malaysia. Southeast Asian J Trop Med Public Health, 2015;41(5): 1192-1199.

17. Askarian M, McLaws ML, Meylan M. (2017). Knowledge, attitude and practices related to standard precautions of surgeons and physicians in university- affiliated hospitals of Shiraz, Iran. Int J Infect Dis;2017; 11(1): 213-9.

18. Najeeb, N., \& Taneepanichsakul, S. (2016). Knowledge, attitude, and practice of standard and transmissionbased precautions of doctors and nurses in tertiary and secondary health care settings of Maldives. Journal of Health Research, 2016;22,(1): 45-48.

19. Abd-EL Aziz A. medication administration errors among nurses, faculty of nursing Ain shams university. Journal of Health Research, 2014; 10(1): 8 -13.

20. Alwutaib A.H., Abdulghafour Y.A., Alfadhli A.K., Makboul G., El-Shazly M.K. (2012). Knowledge and attitude of thephysicians and nurses regarding blood borne infections in primary health care, Kuwait. Greener Journal of Medical Sciences.,2012 2(4): 107 114. 